\title{
Internet of Things-Based Agricultural Mechanization Using Neural Network Extreme Learning on Rough Set
}

\author{
Jian Chen, Jiangxi University of Engineering, China \\ Xiaohua Chen, Jiangxi University of Engineering, China \\ Qingyan Zeng, Jiangxi University of Engineering, China \\ Ishbir Singh, Gulzar Group of Institutions, Ludhiana, India \\ Amit Sharma, Gulzar Group of Institution, Ludhiana, India
}

\begin{abstract}
Recently, the basic functioning of monitoring in internet of things (IoT) is to apply the monitored data to the database for the regular analysis through mobile or computer platform. The purpose of this article is to highlight the application scope of IoT knowledge and to present the model of agricultural IoT for prediction by studying the influence of IoT technology towards modern agriculture. In order to explore the uncertain characteristics of the development of agricultural mechanization, the evaluation index system is simplified through the existing rough set theory. The neural network model is established with five random provinces and cities in 31 provinces and municipalities as test samples. By comparing the data of the neural network model established before and after the reduction, the results show that the index coefficient is reduced by about $60 \%$ based on the fixed information before and after the reduction. The simulation evaluation accuracy established by the artificial neural network model is $100 \%$, which is consistent with the results of the original index system.
\end{abstract}

\section{KEYWORDS}

Agricultural Mechanization, Artificial Neural Network, Evaluation, Internet of Things, Rough Set Theory

\section{INTRODUCTION}

At present, the economy of China has developed rapidly, and new technologies have played a significant role in the field of management and agricultural. China is a big farming country in the world. When compared with other advanced countries, there is huge scope of improvement in agricultural development which is still lagging behind China (Bu \& Wang, 2019). There is still plenty of improvement required in terms of capital investment considering the challenges in infrastructure construction, which can improve the current situations provide better infrastructure of agricultural (Xu et al., 2020). 
Implementing IoT technology towards the process of agricultural development can successfully increase the strong development of China's farming production. The agricultural IoT is one of the most complex system as it involves the study of multidisciplinary fields. Currently, with the constant expansion of recent technology, existing farming technology, communication and smart devices have been widely implemented in agriculture (Ayaz et al., 2019). The crucial technologies of the agricultural IoT is further distributed into multiple layers, that includes transport layer, sensing, application and the processing layer. The development of IoT and artificial intelligence plays a significant role in solving the issues related to architecture and perception for the deployment of smart device and problems associated to them. The constant advancement has modernized the agriculture domain and improves the agricultural production through efficient management. This is a requirement for the continuous development of agriculture technology and its wide acceptance. The modern agricultural technology can not only effect the reduction in cost agricultural process, but also provides the improvement the improvement. Currently in China, with the advancement in technology and adoption of various smart devices towards agriculture the IoT technology has continuously enhanced its place in recent farming management, and its application collection is also increasing ( $\mathrm{Li}$ et al., 2019).

The development of agriculture is the stepping stone of the country's development of mechanization, and it is the only criterion to measure the development of agricultural mechanization in a country (Gao et al., 2017). The standards for the development of agricultural mechanization can be derived from the amount of peasants' cultivation and the harvest status after autumn. For the standard assessment of agricultural mechanization development, it can be judged from four aspects: comprehensive index method, scoring method, analytic hierarchy process and fuzzy evaluation method (Dogra et al., 2020; Selvi \& Chandrasekaran, 2020). Because it is necessary to collect some data and information for use, and it is difficult to collect this type of data. These four identification methods are not accurately judged. Only approximate probability methods are used. At the same time, the data collection process is more complicated, especially in small areas. The development of agricultural mechanization in China is difficult to implement.

This research mainly discusses the uncertain characteristics of the development of agricultural mechanization. Based on the original multi-level fuzzy comprehensive evaluation method. The technical advantages of artificial neural networks and rough set paradoxes are combined, and a method based on neural network and rough set paradoxes is proposed. Evaluation methods, mechanization level and actual evaluation and testing.

The rest of the manuscripts is organized as the most recent work and recent advances in the field of smart agriculture is discussed in Section 2 i.e., Literature Review section. The proposed architectural model for mechanization is discussed in section 3 which includes the index selection and index evaluation processes. The result and analysis of the proposed model is described in Section 4 which includes the topology of the feed forward neural network for agriculture mechanization. At last the conclusion from the observed results is described in section 5 .

\section{LITERATURE}

With the continuous development of IoT technology and its support towards various application relevant to agriculture that solves the issues related to agriculture are discussed (Roopaei et al., 2017; Sharma, Kumar, \& Kaur, 2019). China is presently in the translational where the modern agricultural equipment's are utilized and deployed. The deployment of this modern technology along with the combination of agricultural information approach for the continuous development of industrial chain of agricultural application (Lakhwani et al., 2019; Sharma, Singh, Sharma et al, 2019). The adoption of IoT technology and artificial intelligence not only strengthen the links between agricultural domain and scientific research but also requires scientific research departments to strengthen the efforts to break through the agricultural IoT technologies in dissimilar departments (Sinha et al., 2019; Xie et al., 2020). 
Fei et al. proposed a rough set prediction analysis method for the thermal insulation performance of composite walls in hot summer and cold winter areas in order to improve the accuracy of the algorithm. Firstly, the structure and parameters of three kinds of walls used in the study are given, and the corresponding thermal insulation physical model and the existing problems are described. Secondly, the rough set is introduced and combined with its advantages in dealing with uncertain, inaccurate and incomplete data, to realize the evaluation and analysis of the insulation performance of composite wall. Finally, the effectiveness of the proposed method is verified by simulation experiments (Fei et al., 2019).

Lei et al. proposed a comprehensive indoor air quality evaluation method combining rough set with wavelet neural network. The original data of environmental parameters affecting the indoor air quality of shopping malls were obtained through field tests of indoor air in 6 shopping malls in Beijing, Wuhan and Guangzhou. First of all, the roughness set is used to reduce the dimension of the features that affect indoor air quality, remove the unimportant features, and obtain the important environmental parameters that affect indoor air quality. These important environmental parameters are taken as the input parameters of the wavelet neural network. Then the structure of wavelet neural network is determined and the model of indoor air quality evaluation based on rough set and wavelet neural network is established. Finally, the model is applied to the evaluation of indoor air quality in shopping malls (Lei et al., 2019). Xie et al. designed a portable system based on adaptive neural network, which can obtain sound quality evaluation results similar to those of human foremen. The system consists of binaural microphone, signal conditioning unit (SCU) and mobile phone. First, the sound is sensed by binaural microphones, processed by SCU and collected by mobile phones. After noise reduction, the objective parameters of initial sound quality are calculated, and then the accurate objective parameters are obtained from the initial parameters through the trained neural network model. To train the model, a portable system and a head system were used to simultaneously collect sound samples as input and output sample sets under different conditions. After pre-processing the input sample, the wavelet entropy eigenvalue based on the best TR is obtained (Xie et al., 2019).

\section{DESIGN OF SMART AGRICULTURAL MODEL}

One of the appllication of Internet of Things technology is agricultural IoT for the production of agricultural products and management of agricultural equipments alonog with data synchronization. The technology utilizes identification system, GPS enabled smart devices, data collection on real time basis, and its analysis on regular basis through cloud computing for knowing the agricultural production and livestocks. The information is transmitted through wireless means utilizing Wireless Sensor Networks (Sharma et al., 2017). The collected information from the field is processed and analysed for acquiring the useful information through automation of agricultural automation and intelligent management. The agricultural automation leads to achieve high production yields of better quality with higher efficiency. To achieve the efficieny of higher quality products and the architecture of the agricultural model based on IoT is categorized into three layers: recognition layer, network layer and processing layer.

Figure 1, represents the architecture model of smart agriculture based on Internet of Things. The architecture represents three layers of operation where working is carried out from layer 3 to layer 1 . The layer 3 is based on the deployment of smart devices in field of interest (agricultural land). The deployed devices collects the field data on real time basis and transfers the sensed information towards respective cluster heads. The layer 2 is responsible for the communication of sensed field information towards first layer of operation. This layer communicates information wirelessly considering quality of service parameters into account. The layer 1 gathers the field data and stores the entries on real time basis on cloud platform for the analysis and decision making.

The overall structure of the proposed architectural model is depicted in Figure 2. The information collection is carried out through the deployment phase which consists of wireless nodes that integrate 
Figure 1. Architecture of smart agricultural model based in Internet of Things

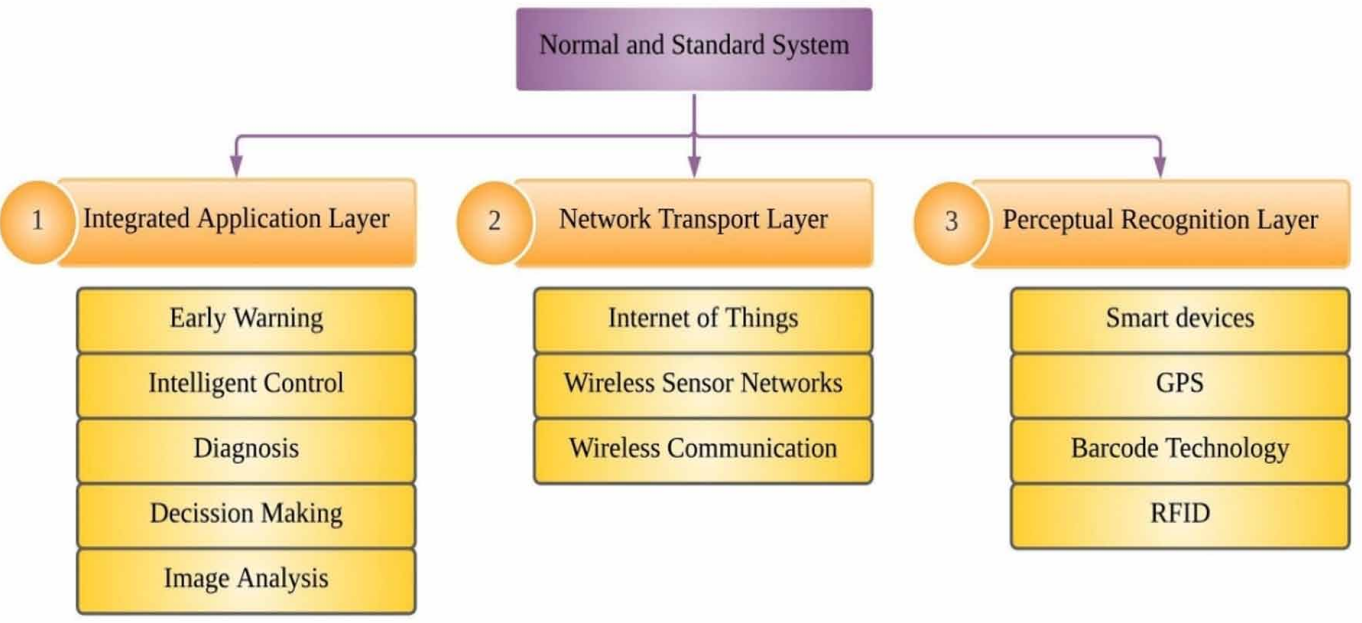

Figure 2. Structural diagram of the proposed agricultural system

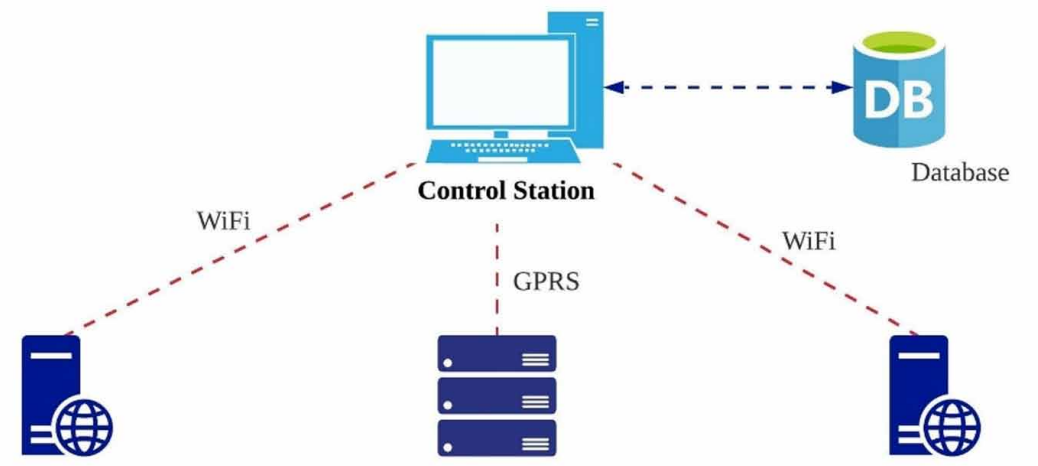

Intelligent Network

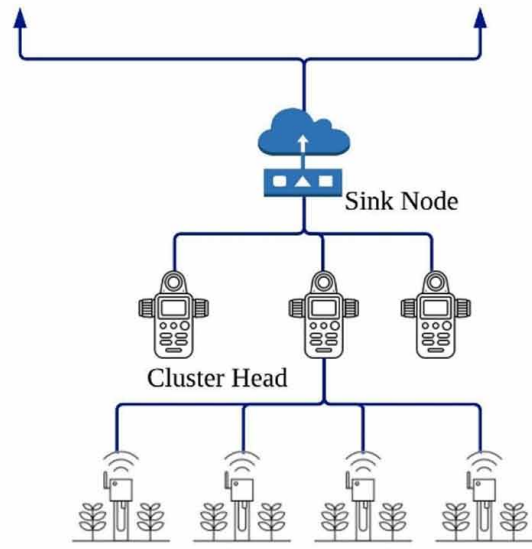

Field Sensors at Location 1
Intelligent Network

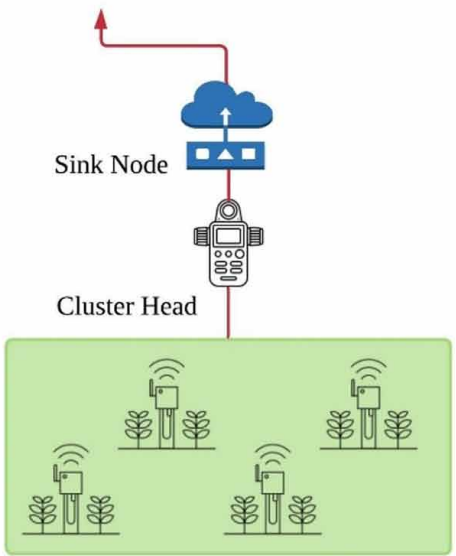

Field Sensors at Location 2 
various sensor nodes for the collection purpose. The collected information from the field is regularly by defining the working frequency, and then the acquired data is communicated wirelessly to the control station. The collected field data is transferred to the control station through cluster head and sink node. The cluster head collects the data from their respective group of sensor modules and transfers the information to the sink node. The sink node further communicates the data to control station. The proposed system implements various topologies for the network transmission. The architecture uses intelligent network for which wirelessly uploads the data to control station and further which is stored and analyzed. The intelligent network topology is efficient in dealing with long range communications and consumes less power.

\subsection{Principles for Index Selection}

The important sign of the degree of regional agricultural modernization is the development level of agricultural mechanization, which reflects the degree of agricultural production mechanization, which directly affects agricultural production efficiency, crop yield and agricultural output (Zhao, 2019). Saving labour, saving resources and improving the efficiency of agricultural labour production play an important role in the development of regional agricultural mechanization. The purpose of the establishment of the evaluation index system for the development level of agricultural mechanization is to provide a basis for the quantification of the development level of regional agricultural mechanization and the analysis of its evolutionary trend (Chen et al., 2020). The following regulations should be followed when the agricultural mechanization level indicator is established:

It reflects the input of agricultural mechanization and the output function of agricultural mechanization in agricultural production. The input and output elements included in the indicators are capital, labour, energy, technology, etc., as well as crop yield, crop output value and income.

i. The progress of agricultural mechanization is restricted by many factors such as social economy, technology, education level and social structure. Therefore, the formulation of evaluation indicators should be considered from multiple angles and levels.

ii. Due to the differences in social economy, resources, development level and technological level among different regions, the existing methods should be referred to while regional differences should be considered when formulating the index system. According to the actual situation of different regions, formulate an index system suitable for local development characteristics.

iii. Due to the differences in different regions between social economy, energy, development level and technological level, current methods should be considered when formulating the index system. Develop an index system in line with local characteristics in accordance with local conditions.

\subsection{Evaluation Index System}

Based on the exploration of relevant documents at home and abroad and the actual situation of agricultural machinery in my country, according to the task requirements of the agricultural mechanization department of the Ministry of Agriculture, it is proposed to adopt a quantitative and qualitative integration method for the development level of agricultural mechanization, and establish a fuzzy clustering model of mechanized classification. At the same time, this model is used to carry out a classification study on the development level of agricultural mechanization in the national and provincial cities (Bahnas \& Bondok, 2019). The evaluation index system consists of 2 levels, 6 aspects and 10 indexes. The details are shown in Figure 3.

After appraisal and exploration, expert discussion and command department, the weights of six aspects have been determined, and the index definition values shall be determined according to the actual situation. Using the analysis of the principle of fuzzy clustering, the results of the classification and evaluation of the level of agricultural mechanization in China in 2016 were obtained as presented 
Figure 3. Agricultural mechanization level evaluation index system

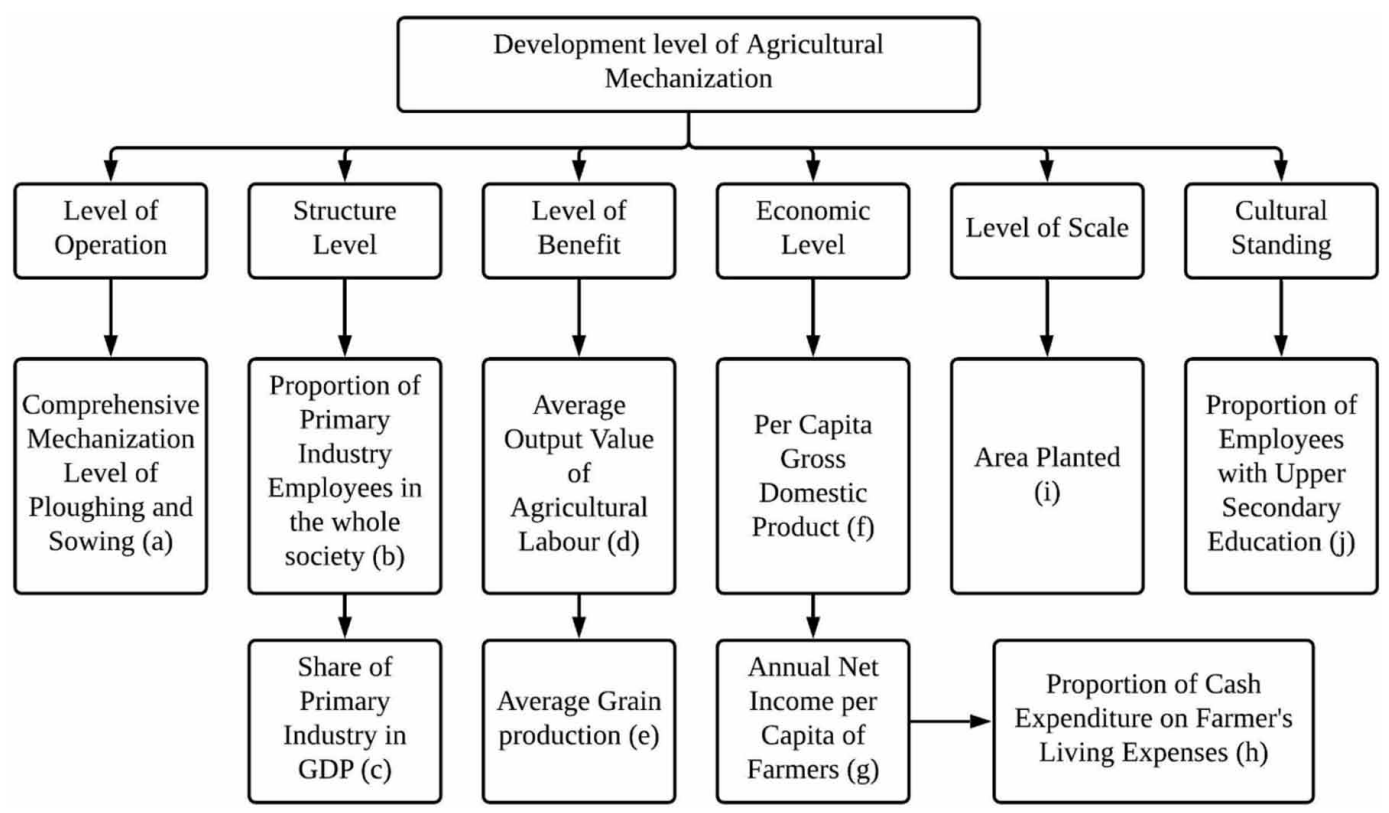

in Table 1. The development level of agricultural mechanization is divided into four types of regions as presented in Table 2 .

From the data analysis in Table 1, although the evaluation index system and analysis model of agricultural mechanization development level have been established, the analysis workload of collecting dozens of data in a region is relatively large, and some data may not be collected (Thakur et al., 2020). Regardless of whether these indicators are necessary, whether the indicator system can be improved, and more accurate classification results can be obtained with fewer indicators. For this reason, artificial neural networks and rough set paradox methods are used to establish agricultural mechanization level evaluation indicators and evaluation models. Simple system (Yuanzhi et al., 2018).

\section{RESULT AND ANALYSIS}

The classification and evaluation of the development level of agricultural mechanization shown in Table 1 is essentially an information system. In order to facilitate the discussion, first expressed the knowledge of the information system. Each row in the table represents a decision criterion, and each column represents an attribute. In the first column of the table, using 1, 2, 3 and so on. Article 32 indicates that there are 32 rules for evaluating the development level of agricultural mechanization. In the first row of the table, from left to right, use a, b, c, d, e...J to represent the operation level, and the staff structure level...K to represent the evaluation results of 10 evaluation indicators such as education level. Therefore, Table 1 can be expressed as an information system $T=(U, A, C, D)$, the domain $\mathrm{U}$ is a theory, $\mathrm{C}=(\mathrm{a}, \mathrm{b}, \mathrm{c}, \mathrm{d}, \mathrm{e}, \mathrm{f}, \mathrm{g}, \mathrm{h}, \mathrm{i}, \mathrm{j})$ Is the condition attribute set of the information system, $D=\{k\}$ is the decision attribute set; $A=C \cup D$.

Implement knowledge reduction through rough set theory for the information system shown in Table 1. 
Table 1. The agricultural mechanization level in mainland China was classified and evaluated in 2016

\begin{tabular}{|c|c|c|c|c|c|c|c|c|c|c|c|c|}
\hline $\begin{array}{l}\text { S. } \\
\text { No. }\end{array}$ & Place name & $\mathbf{a}$ & b & c & d & e & $\mathbf{f}$ & $\mathbf{g}$ & h & $\mathbf{i}$ & $\mathbf{j}$ & $\mathbf{k}$ \\
\hline 1 & China & 2 & 2 & 2 & 3 & 2 & 2 & 2 & 3 & 3 & 3 & 2 \\
\hline 2 & Beijing & 1 & 1 & 1 & 1 & 1 & 1 & 1 & 1 & 1 & 1 & 1 \\
\hline 3 & Tianjin & 1 & 1 & 1 & 1 & 1 & 1 & 1 & 1 & 1 & 1 & 1 \\
\hline 4 & Hebei & 1 & 2 & 2 & 2 & 2 & 2 & 2 & 2 & 2 & 2 & 2 \\
\hline 5 & Shanxi & 2 & 2 & 1 & 3 & 3 & 3 & 3 & 3 & 2 & 2 & 2 \\
\hline 6 & $\begin{array}{c}\text { Inner } \\
\text { Mongolia }\end{array}$ & 2 & 3 & 4 & 2 & 1 & 3 & 3 & 3 & 1 & 2 & 2 \\
\hline 7 & Liaoning & 1 & 1 & 1 & 1 & 2 & 1 & 2 & 2 & 2 & 1 & 1 \\
\hline 8 & Jilin & 2 & 2 & 3 & 1 & 1 & 2 & 2 & 2 & 1 & 2 & 2 \\
\hline 9 & Heilongjiang & 1 & 1 & 2 & 1 & 1 & 2 & 2 & 3 & 1 & 1 & 1 \\
\hline 10 & Shanghai & 1 & 1 & 1 & 1 & 1 & 1 & 1 & 1 & 1 & 1 & 1 \\
\hline 11 & Jiangsu & 1 & 1 & 1 & 1 & 2 & 1 & 1 & 2 & 3 & 2 & 1 \\
\hline 12 & Zhejiang & 2 & 2 & 1 & 2 & 3 & 1 & 1 & 1 & 4 & 3 & 2 \\
\hline 13 & Anhui & 2 & 3 & 4 & 3 & 3 & 3 & 3 & 3 & 3 & 3 & 2 \\
\hline 14 & Fujian & 3 & 2 & 2 & 1 & 3 & 1 & 2 & 2 & 4 & 3 & 2 \\
\hline 15 & Jiangxi & 3 & 3 & 4 & 3 & 2 & 3 & 2 & 3 & 2 & 3 & 3 \\
\hline 16 & Shandong & 1 & 3 & 2 & 2 & 2 & 2 & 2 & 2 & 3 & 3 & 2 \\
\hline 17 & Henan & 1 & 3 & 3 & 3 & 3 & 3 & 3 & 3 & 3 & 2 & 2 \\
\hline 18 & Hubei & 3 & 2 & 3 & 2 & 2 & 2 & 2 & 4 & 2 & 2 & 2 \\
\hline 19 & Hunan & 3 & 3 & 4 & 3 & 3 & 3 & 2 & 3 & 4 & 3 & 3 \\
\hline 20 & Guangdong & 3 & 2 & 1 & 1 & 3 & 1 & 1 & 1 & 4 & 2 & 2 \\
\hline 21 & Guangxi & 3 & 4 & 4 & 3 & 4 & 3 & 3 & 3 & 4 & 3 & 3 \\
\hline 22 & Hainan & 4 & 4 & 4 & 1 & 3 & 2 & 3 & 3 & 2 & 2 & 3 \\
\hline 23 & Chongqing & 4 & 3 & 3 & 4 & 3 & 3 & 3 & 4 & 4 & 4 & 3 \\
\hline 24 & Sichuan & 4 & 4 & 4 & 4 & 3 & 4 & 3 & 4 & 4 & 4 & 4 \\
\hline 25 & Guizhou & 4 & 4 & 4 & 4 & 4 & 4 & 4 & 4 & 4 & 4 & 4 \\
\hline 26 & Yunnan & 4 & 4 & 3 & 4 & 4 & 4 & 4 & 3 & 4 & 4 & 4 \\
\hline 27 & Tibet & & & 4 & 4 & 4 & 4 & 4 & 3 & 4 & 4 & 4 \\
\hline 28 & Shaanxi & 2 & 3 & 2 & 4 & 4 & 4 & 4 & 3 & 3 & 2 & 3 \\
\hline 29 & Gansu & 2 & 3 & 3 & 4 & 4 & 4 & 4 & 4 & 2 & 4 & 3 \\
\hline 30 & Qinghai & 2 & 3 & 2 & 4 & 4 & 4 & 4 & 4 & 3 & 4 & 3 \\
\hline 31 & Ningxia & 2 & 3 & 3 & 3 & 2 & 4 & 3 & 3 & 1 & 3 & 3 \\
\hline 32 & Xinjiang & 1 & 3 & 3 & 1 & 1 & 2 & 3 & 2 & 1 & 3 & 2 \\
\hline
\end{tabular}

i. Rule reduction: Delete duplicate decision table rules in the rule row. Since the information presented in rules 2, 3 and 10 is completely consistent with the results, rules 3 and 10 are omitted.

ii. Attribute reduction: Remove unnecessary columns from the decision table. From the decision table of the information system, delete the attributes in the attribute set one by one, and then 
Table 2. Regional classification of agricultural mechanization in mainland China in 2016

\begin{tabular}{|c|c|l|}
\hline \multirow{2}{*}{ Category } & \multicolumn{2}{|c|}{ Area } \\
\hline \multirow{2}{*}{ One type } & north & Beijing, Tianjin, Heilongjiang, Liaoning \\
\cline { 2 - 3 } & south & Shanghai, Jiangsu \\
\hline \multirow{2}{*}{ Second category } & north & Xinjiang: Hebei, Henan, Jilin, Shandong, Inner Mongolia, Shanxi \\
\cline { 2 - 3 } & south & Zhejiang, Anhui, Guangdong, Hubei, Fujian \\
\hline \multirow{2}{*}{ Four categories } & north & Ningxia, Shaanxi, Qinghai, Gansu \\
\cline { 2 - 3 } & south & Hunan, Jiangxi, Guangxi, Hainan, Chongqing \\
\hline
\end{tabular}

check the decision table for each deleted attribute. If there is no new inconsistency, the attribute is reducible (that is, the decision table after deleting the attribute has the same value as the original. The same decision effect as the decision table). Otherwise, the attribute cannot be cancelled. This method is called attribute reduction data analysis method.

The topology of the architecture based on multi-layer perception feed forward neural network is depicted in Figure 4.

Based on the availability of data and considering the most representative data among all, set of input items which includes the certain explanatory parameters, were elected as the premium candidate of inputs for all the outcomes. The data is checked for its representativeness for the uniform distributions. The feed forward regression technique is employed for different collected input values in order to achieve mechanization functions as output. Considering training process selective parameters are transferred to the artificial neural network model. The selective parameters represents essential factors for an efficient agricultural system and furthers these factors are indicated as the mechanization status. The observed results produces superior performance during the learning process. Underlying the concept of mechanization, level of mechanization and mechanization index were computed in order to evaluate the characterization of agricultural system.

Figure 4. Topology of network based on feed forward neural network

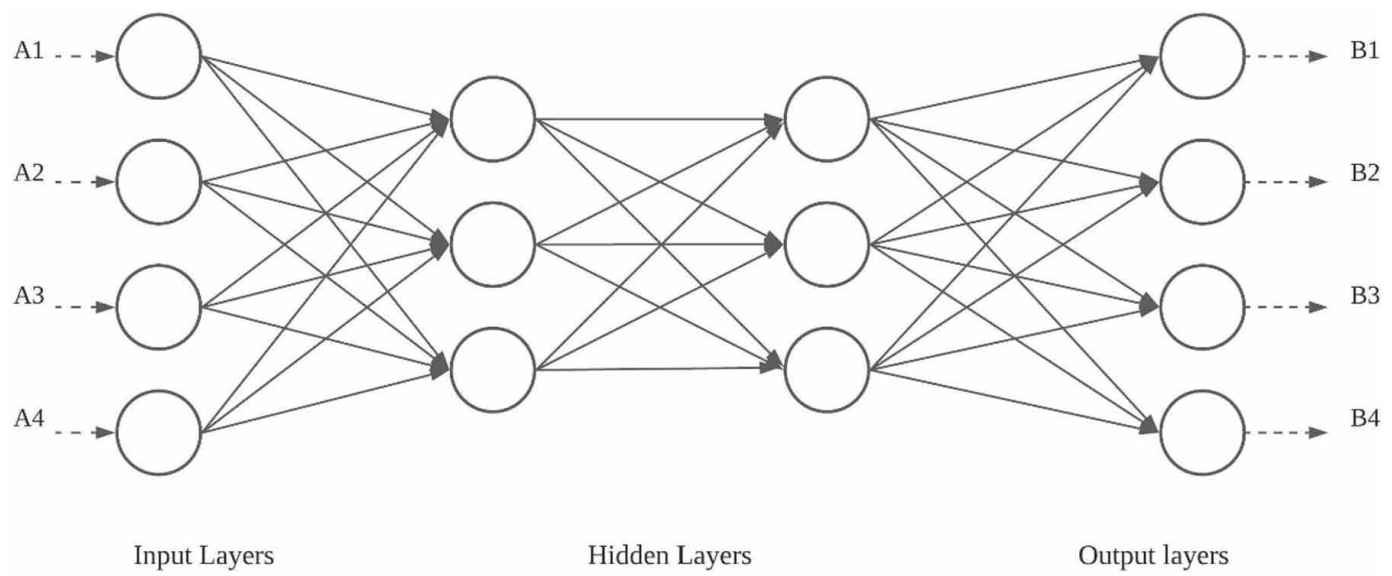




$$
L_{m}=\sum_{i=1}^{n} \frac{Q_{i} \times \epsilon}{A_{i}}
$$

Equation 1, represent the calculation of level of mechanization $\left(L_{m}\right)$, where $Q_{i}$ is the power, $\in$ is the correction factor considered as 0.72 for the power utilized and $A_{i}$ represents the agricultural area:

$$
\mathrm{I}_{m}=\frac{1}{n} \sum_{i=1}^{n} \frac{I_{e}}{I_{a}} \frac{A_{i}}{T A_{i}}
$$

Equation 2 represents the calculation mechanization index $\left(\mathrm{I}_{m}\right)$, where $I_{e}$ is the input energy, $I_{a}$ stands for average energy $A_{i}$ is the overall area and $T A_{i}$ represents the complete field area.

There exists multiple structures of ANN various frameworks for the purpose of classification. In this proposed work MLP which is a multi-layer perception is adopted where the number of neurons are arranged to several layers. The first layer is fed by the different patterns of input data and termed as input layer and the outcome provides the reactions for each pattern of input and termed as output layer. There exists various hidden layers in between the input and output layer as depicted in Figure 4.

The ability of generalization of multi-layer perception can be determined by the number of hidden layers. Hence, multi-layer perception is utilized as an important tool which identifies the relationship among the various datasets.

To check the performance of the optimal architecture of feed forward artificial neural network, the architecture network is trained for different units ranging in between 0 to 20 . The network is trained, then tested and validated for each of these units. The subset is validated for 10 number of patterns and these patterns were not implemented initially during the phases of training and testing. The subset was adopted for computing the relation among the observed outcomes from neural network model with the outcomes observed from the computation of Equation 1 and Equation 2. The architecture of network along with the hidden layers were concurrently trained and tested for various units ranging between 0 and 20 for the subsets. The testing dataset is thereby utilized for measuring the accuracy of proposed feed forward artificial neural network for agricultural mechanization. Figure 5 depicts the computed relationship among the architecture output and actual measured output using equations 1 and 2. It is observed from the experimentation that the network comprising with 2 to 8 hidden units presents higher performances. The performance is validated for various hidden layers, and it is observed that single hidden layer presents better results.

Figure 6 depicts the outcomes of sensitivity analyses based on level of mechanization and mechanization index respectively. The sensitivity is analyzed for various inputs of ANN which comprises of (a) Level of Ploughing and Sowing, (b) Proportion of Primary Industry, (c) Share of Primary Industry in GDP, (d) Average Output Value of Agricultural Labour, (e) Average Grain production, (f) Per Capita Gross Domestic Product, (g) Annual Net Income per Capita of Farmers, (h) Proportion of Cash Expenditure on Farmer's Living Expenses, (i) Area planted, (j) Proportion of Employees with Upper Secondary Education and (k) sum of costs. For assessing the validity of proposed model based on neural network, the sensitivity is analyzed for both level of mechanization and mechanization index. The sensitivity of the proposed model were analyzed by observing and matching the outputs created at validation stage with the observed values. The proposed model was trained by eliminating one advisory constraint at a time and keeping other items constant for each pattern. Based on the observed sensitivity for each output only those parameters were elected that presents most effect towards related outputs. 
Figure 5. Relation among the ANN's output and computed output

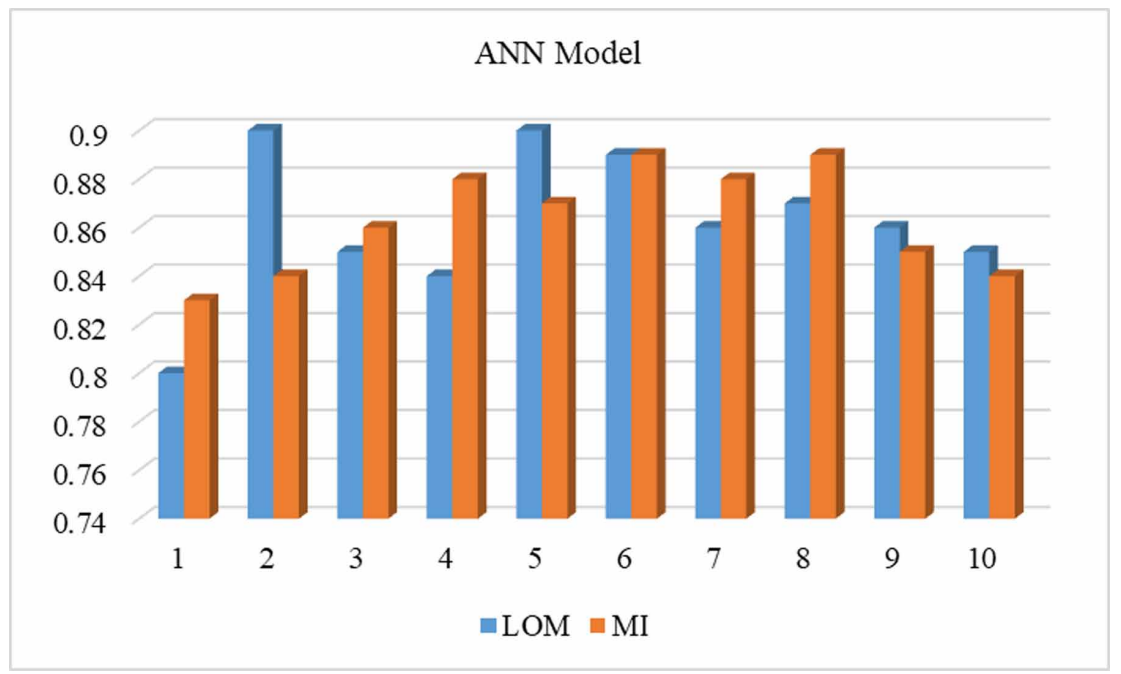

Figure 6. Analysis of Sensitivity based on Level of Mechanization for various ANN inputs

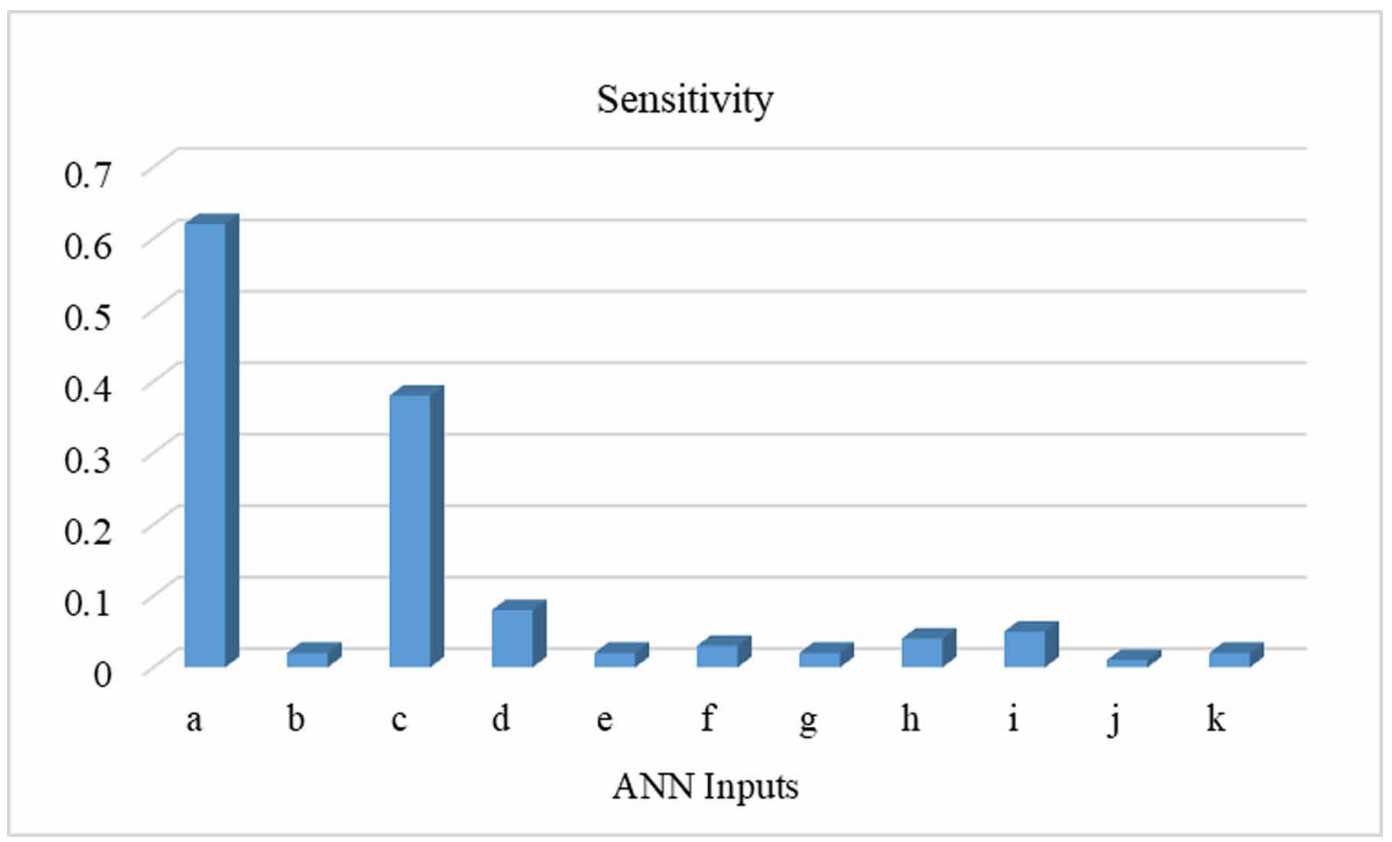

Table 1 is an overall decision table. In the first attribute reduction, the index (attribute) with smaller weight is usually preferentially eliminated. In Table 1 , the attribute reduction in decision table 1 is selected from the last column $\mathrm{j}$ attribute. Cancel column $\mathrm{j}$, check whether the reduced decision table is a consistent decision table, that is, and check whether there are conflicting rules in the table. If the decision table after deleting column $\mathrm{j}$ is a consistent decision table, list $\mathrm{j}$ as a reducible attribute. Similarly, after the attributes of I, h, g, f, and e are reduced, the test shows that j, I, h, g, f, and e are 
all reducible attributes, and the decision Table 3 is obtained (for data analysis to adjust the position of the rule).

If we further reduce Table 3, we can see that eliminating any attribute $a, b$, c, and d will cause contradictory rules (for example, eliminating the contradiction between attribute $\mathrm{d}$ Rule $22 \mathrm{a}$ : $4 \mathrm{~b} 4 \mathrm{c} 4 \rightarrow \mathrm{k} 3$ and Rule 24: a4b4c4 $\rightarrow \mathrm{k} 4$ ), therefore, any attribute a, b, c, and d are irreducible and are the main core. According to the rough set theory, the index coefficients in Table 1 and Table 3 are reduced by $60 \%$, but the information contained in the rules is consistent. The simplest index system for evaluating the development level of agricultural mechanization is thus obtained. The following two sets of index systems before and after the simplification are tested by neural network.

In 31 provinces and municipalities, 5 regions are randomly selected as test samples, such as: Jiangxi, Yunnan, Tianjin, Hebei, Shaanxi. For the remaining 26 provinces and municipalities, index data and results will be used as learning templates for operation. Because Tibet is the first region, two indicator data are missing, so this template is not included in the learning template to ensure its testing results. Since 26 provinces and cities are repeated in the index data after attribute reduction, there are 22 non-repetitive learning templates in the deleted index system neural network. The reduced comparative data of the neural network model established by the index system is shown in Table 4 .

Table 3. Decision table after cancelling $\mathrm{j}, \mathrm{l}, \mathrm{h}, \mathrm{g}, \mathrm{f}$ and $\mathrm{e}$ attributes

\begin{tabular}{|c|c|c|c|c|c|}
\hline Numbering & $\mathbf{a}$ & b & C & D & $\mathbf{K}$ \\
\hline 3 & 1 & 1 & 1 & 1 & 1 \\
\hline 9 & 1 & 1 & 2 & 1 & 1 \\
\hline 4 & 1 & 2 & 2 & 2 & 2 \\
\hline 16 & 1 & 3 & 2 & 2 & 2 \\
\hline 32 & 1 & 3 & 3 & 1 & 2 \\
\hline 17 & 1 & 3 & 3 & 3 & 2 \\
\hline 5 & 2 & 2 & 1 & 3 & 2 \\
\hline 8 & 2 & 2 & 3 & 1 & 2 \\
\hline 1 & 2 & 2 & 2 & 3 & 2 \\
\hline 12 & 2 & 2 & 1 & 2 & 2 \\
\hline 6 & 2 & 3 & 4 & 3 & 2 \\
\hline 13 & 2 & 3 & 4 & 3 & 2 \\
\hline 30 & 2 & 3 & 2 & 4 & 3 \\
\hline 29 & 2 & 3 & 3 & 4 & 3 \\
\hline 31 & 2 & 3 & 3 & 3 & 3 \\
\hline 14 & 3 & 2 & 2 & 1 & 2 \\
\hline 18 & 3 & 2 & 3 & 2 & 2 \\
\hline 19 & 3 & 3 & 4 & 3 & 3 \\
\hline 20 & 3 & 2 & 1 & 1 & 2 \\
\hline 21 & 3 & 4 & 4 & 3 & 3 \\
\hline 22 & 4 & 4 & 4 & 1 & 3 \\
\hline 23 & 4 & 3 & 3 & 4 & 3 \\
\hline 24 & 4 & 4 & 4 & 4 & 4 \\
\hline 26 & 4 & 4 & 3 & 4 & 4 \\
\hline
\end{tabular}


Table 4. Comparison of data of the neural network model established by the two sets of indicators

\begin{tabular}{|l|c|c|c|c|c|c|}
\hline \multicolumn{1}{|c|}{ Project } & $\begin{array}{c}\text { Number of } \\
\text { input units }\end{array}$ & $\begin{array}{c}\text { Number } \\
\text { of hidden } \\
\text { units }\end{array}$ & $\begin{array}{c}\text { Number of } \\
\text { output units }\end{array}$ & $\begin{array}{c}\text { Number } \\
\text { of } \\
\text { samples }\end{array}$ & $\begin{array}{c}\text { Learning } \\
\text { step }\end{array}$ & $\begin{array}{c}\text { Extreme } \\
\text { convergence } \\
\text { factor }\end{array}$ \\
\hline Full index system & 10 & 3 & 1 & 26 & 0.5 & 0.0000003 \\
\hline Index system after reduction & 4 & 2 & 1 & 22 & 0.5 & 0.0000003 \\
\hline
\end{tabular}

The rounding neural network evaluation is studied from the direction of the development level of the integer concept, and the artificial neural network model of the reduced index system and the full index system is established according to the agreed rounding method, and 22 non-repetitive learning sample systems are used for evaluation., The evaluation result is the same as the original standard evaluation. Based on the artificial neural network model, the level of agricultural mechanization among the five regions is evaluated, and the analysis results are shown in Table 5.

Table 5 shows that on the basis of the development level of agricultural mechanization, the evaluation and classification effects of the original complex full index system and the reduced index system are consistent. Taking Shaanxi Province as an example, due to data interference, the result " 2 " obtained by using the full index system evaluation is different from the original result " 3 ". Under the reduction index system, due to the establishment of the artificial neural network model, the simulation evaluation accuracy is $100 \%$, which highlights the goodness of the artificial neural network model.

\section{CONCLUSION}

A new evaluation method of agricultural mechanization level based on artificial neural network and rough set theory is proposed, which can make better use of information. By using rough set theory to simplify the evaluation index system, the data requirement is greatly reduced, the learning speed of neural network is greatly improved, and the manoeuvrability and anti-interference ability of the evaluation system are improved. The neural network model can be easily simulated, evaluated and optimized. The evaluation of other multi-index systems has reference application value. The simulation results of the model show that the prediction and evaluation accuracy is high, and through this model, the influence of various parameters on the development level of agricultural mechanization can be simulated, and the most critical factors can be found out. This model provides a new way to master

Table 5. Comparison of the evaluation results of the indicator system obtained by full index and rough set reduction

\begin{tabular}{|c|c|c|c|c|c|}
\hline \multirow{2}{*}{$\begin{array}{c}\text { Place } \\
\text { name }\end{array}$} & \multirow{2}{*}{$\begin{array}{c}\text { Standard } \\
\text { Evaluation }\end{array}$} & \multicolumn{2}{|c|}{$\begin{array}{c}\text { Full index evaluation classification } \\
\text { results }\end{array}$} & \multicolumn{2}{c|}{$\begin{array}{c}\text { Evaluation and classification results of the } \\
\text { index system after reduction }\end{array}$} \\
\cline { 3 - 6 } & & $\begin{array}{c}\text { Evaluation } \\
\text { classification }\end{array}$ & $\begin{array}{c}\text { Rounded } \\
\text { value }\end{array}$ & $\begin{array}{c}\text { Evaluation } \\
\text { classification }\end{array}$ & Rounded value \\
\hline Tianjin & 1 & 1.03 & 1 & 1.02 & 1 \\
\hline Hebei & 2 & 1.81 & 2 & 1.65 & 2 \\
\hline Jiangxi & 3 & 2.93 & 3 & 2.78 & 3 \\
\hline Yunnan & 4 & 4.28 & 4 & 3.76 & 3 \\
\hline Shaanxi & 3 & 2.36 & 2 & 2.86 & 3 \\
\hline
\end{tabular}


the internal law of each index of agricultural mechanization development evaluation system and analyse the level of agricultural mechanization development. The evaluation model of agricultural mechanization development level based on rough set theory and neural network is about $60 \%$ less than the original one. 


\section{REFERENCES}

Ayaz, M., Ammad-Uddin, M., Sharif, Z., Mansour, A., \& Aggoune, E. H. M. (2019). Internet-of-Things (IoT)based smart agriculture: Toward making the fields talk. IEEE Access: Practical Innovations, Open Solutions, 7, 129551-129583. doi:10.1109/ACCESS.2019.2932609

Bahnas, O. T., \& Bondok, M. Y. (2019). Effect of Rotary Plough and Precision Land Levelling on Faba Bean Response to Organic Fertilization. AMA. Agricultural Mechanization in Asia, Africa and Latin America, 50(3), $7-13$.

Bu, F., \& Wang, X. (2019). A smart agriculture IoT system based on deep reinforcement learning. Future Generation Computer Systems, 99, 500-507. doi:10.1016/j.future.2019.04.041

Chen, X., Shuai, C., Zhang, Y., \& Wu, Y. (2020). Decomposition of energy consumption and its decoupling with economic growth in the global agricultural industry. Environmental Impact Assessment Review, 81, 106364. doi:10.1016/j.eiar.2019.106364

Dogra, J., Jain, S., Sharma, A., Kumar, R., \& Sood, M. (2020). Brain tumor detection from MR images employing fuzzy graph cut technique. Recent Advances in Computer Science and Communications (Formerly: Recent Patents on Computer Science), 13(3), 362-369.

Fei, X., Youfu, S., \& Xuejun, R. (2019). A rough set data prediction method based on neural network evaluation and least squares fusion. Cluster Computing, 22(5), 11641-11646. doi:10.1007/s10586-018-2641-X

Gao, X., Chen, L., Sun, B., \& Liu, Y. (2017). Employing SWOT analysis and normal cloud model for water resource sustainable utilization assessment and strategy development. Sustainability, 9(8), 1439. doi:10.3390/ su9081439

Lakhwani, K., Gianey, H., Agarwal, N., \& Gupta, S. (2019). Development of IoT for smart agriculture a review. In Emerging Trends in Expert Applications and Security (pp. 425-432). Springer. doi:10.1007/978-981-132285-3_50

Lei, L., Chen, W., Xue, Y., \& Liu, W. (2019). A comprehensive evaluation method for indoor air quality of buildings based on rough sets and a wavelet neural network. Building and Environment, 162, 106296. doi:10.1016/j.buildenv.2019.106296

Li, N., Xiao, Y., Shen, L., Xu, Z., Li, B., \& Yin, C. (2019). Smart Agriculture with an Automated IoT-Based Greenhouse System for Local Communities. Advances in Internet of Things, 9(02), 15-31. doi:10.4236/ ait.2019.92002

Roopaei, M., Rad, P., \& Choo, K. K. R. (2017). Cloud of things in smart agriculture: Intelligent irrigation monitoring by thermal imaging. IEEE Cloud Computing, 4(1), 10-15.

Selvi, S., \& Chandrasekaran, M. (2020). Framework to forecast environment changes by optimized predictive modelling based on rough set and Elman neural network. Soft Computing, 24(14), 10467-10480. doi:10.1007/ s00500-019-04556-5

Sharma, A., Ansari, M. D., \& Kumar, R. (2017, September). A comparative study of edge detectors in digital image processing. In 20174 th International Conference on Signal Processing, Computing and Control (ISPCC) (pp. 246-250). IEEE. doi:10.1109/ISPCC.2017.8269683

Sharma, A., Kumar, R., \& Kaur, P. (2019, November). Study of Issues and Challenges of Different Routing Protocols in Wireless Sensor Network. In 2019 Fifth International Conference on Image Information Processing (ICIIP) (pp. 585-590). IEEE. doi:10.1109/ICIIP47207.2019.8985915

Sharma, A., Singh, P. K., Sharma, A., \& Kumar, R. (2019). An efficient architecture for the accurate detection and monitoring of an event through the sky. Computer Communications, 148, 115-128. doi:10.1016/j. comcom.2019.09.009

Sinha, A., Shrivastava, G., \& Kumar, P. (2019). Architecting user-centric internet of things for smart agriculture. Sustainable Computing: Informatics and Systems, 23, 88-102. doi:10.1016/j.suscom.2019.07.001 
Thakur, S. S., Singh, M., \& Chandel, R. (2020). Yield and Economics Attributed Study of Direct Seeding and Transplanting Method on Beds for Onion (Allium Cepa L.) Cropwith Pneumatic Precision Multicrop Planter and Manual Transplanting Method Along With Rotary Tiller Cum Bed Former in Indian Conditions. AMA. Agricultural Mechanization in Asia, Africa and Latin America, 50(4), 76-87.

Xie, X., Ma, Z., Ye, J., Zeng, F., Fan, W., \& Chen, B. (2019). Research and development of sound quality in portable testing and evaluation system based on self-adaptive neural network. Applied Acoustics, 154, 138-147. doi:10.1016/j.apacoust.2019.04.039

Xie, Z., Du, L., Lv, X., Wang, Q., Huang, J., Fu, T., \& Li, S. (2020). Evaluation and Analysis of Battery Technologies Applied to Grid-Level Energy Storage Systems Based on Rough Set Theory. Transactions of Tianjin University, 1-8.

Xu, X. L., Chen, H. H., \& Zhang, R. R. (2020). The Impact of Intellectual Capital Efficiency on Corporate Sustainable Growth-Evidence from Smart Agriculture in China. Agriculture, 10(6), 199. doi:10.3390/ agriculture10060199

Yuanzhi, Y. A. N. G., Zhongliang, Z. H. O. U., Hongqiang, L. I. U., Tian, K. O. U., \& Xiangyu, F. A. N. (2018). Threat evaluation method of air target based on information entropy and rough set. Journal of Beijing University of Aeronautics and Astronautics, 44(10), 2071.

Zhao, C. (2019). State-of-the-art and recommended developmental strategic objectivs of smart agriculture. Smart Agriculture, 1(1), 1. 